\title{
Análise da evolução do número de patentes relacionadas ao processo de ordenha
} Analysis of the evolution of the number of patents related to the milking process

\section{Fernando Ferrari Putti ${ }^{*}$ (1), Bruno César Góes², Luís Roberto Almeida Gabriel Filho², Diogo de Lucca Sartori', Marcelo George Mungai Chacur ${ }^{3}$, Camila Pires Cremasco ${ }^{1}$}

'Universidade Estadual Paulista "Júlio de Mesquita Filho" (UNESP), Curso de Engenharia de Biossistemas, Tupã/SP - Brasil

2Universidade Estadual Paulista "Júlio de Mesquita Filho" (UNESP), Curso de Administração, Tupã/SP - Brasil

${ }^{3}$ Universidade do Oeste Paulista (UNOESTE), Curso de Medicina Veterinária, Presidente Prudente/SP - Brasil

\section{*Corresponding Author}

Fernando Ferrari Putti, Universidade Estadual Paulista "Júlio de Mesquita Filho" (UNESP), Curso de Engenharia de Biossistemas, Av. Domingos da Costa Lopes, 780, CEP: 17602-496, Tupã/SP - Brasil, e-mail: fernandoputti@tupa.unesp.br

Cite as: Analysis of the evolution of the number of patents related to the milking process. Braz. J. Food Technol., v. 21, e2017017, 2018.

Received: Feb. 22, 2017; Accepted: Mar. 20, 2018

\section{Resumo}

A economia leiteira abrange produtos de grande destaque para o agronegócio brasileiro. Sua produção apresentou crescimento nas últimas décadas, podendo atribuir-se a fatores, como o aumento do número de vacas ordenhadas e/ou adoção de animais com maior produtividade no rebanho, e a inserção de tecnologia no processo de produção leiteira. Assim, o objetivo deste trabalho foi quantificar, junto à base de dados do Instituto Nacional da Propriedade Industrial INPI, a totalidade de registros de patentes vinculadas à atividade da produção leiteira, principalmente durante a fase de ordenha, verificando se há correlação entre o número de registros e o aumento de produtividade e/ou o aumento do número de animais em lactação. Foram consultadas na base de dados do INPI, registros de patentes relacionadas ao processo de ordenha realizadas no período entre 1975 e 2015 No ano de 1996, foi promulgada a Lei n. ${ }^{\circ}$ 9.279, que garante os direitos e obrigações relativos à propriedade industrial, momento em que ocorre maior procura pelos pedidos de registros. Entretanto, o número de pedidos de registros não foi significativo, se comparado com o período após 2006, quando entrou em vigor no Brasil a Instrução Normativa 51, que regula todo o processo envolvido na produção leiteira, quando, então, ocorreu um aumento expressivo do número de registros na base de dados do INPI. Concluiu-se, assim, que o aumento do número de patentes no período analisado coincidiu com o aumento da produção de leite, relacionado ao maior número de animais ordenhados e/ou maior produção de leite no rebanho brasileiro, o que torna a evolução tecnológica no setor ser mencionada como uma das causas da melhoria da qualidade dos produtos lácteos.

Palavras-chave: INPI; Tecnologia; Produção; Leite.

\section{Abstract}

The dairy economy is one of the most important sectors of Brazilian agribusiness. Dairy production showed growth over the last few decades, which can be attributed to factors such as: an increase in the number of milked cows and/or the adoption of more productive animals in the dairy herd, and the insertion of technology into the dairy production process. Thus, the objective of this study was to quantify, together with the Brazilian National Institute of Industrial Property - INPI database, all registrations of patents related to the milk production activity, mainly during the milking phase, verifying if there is any correlation between the number of registrations and the increase in productivity and / or the increase in number of lactating animals. Patent records related to the milking process carried out between 1975 and 2015 were consulted in the INPI database. The Brazilian law No. 9,279 was enacted in 1996, which guarantees the rights and obligations related to industrial property, and at that time a greater demand for registrations occurred, although this was not significant when compared with the period after 2006, when Normative Instruction 51 came into force, which regulates the whole process involved in milk production, obtaining a significant increase in the number of registrations in the INPI database. It was thus concluded that the increase in the number of patents during the period analyzed coincided with the increase in milk production, which was related to the greater number of milked animals and/or higher milk yields in the Brazilian herd, which makes the technological evolution in the sector be mentioned as one of the causes of the improvement in quality of dairy products.

Keywords: INPI; Technology; Production; Milk. 


\section{Introdução}

A economia leiteira abrange produtos de grande importância para o agronegócio brasileiro, ficando à frente de produtos tradicionalmente consagrados, como o caso do café beneficiado e o do arroz (ARAÚJO; SILVA, 2014; SOUZA et al., 2013; BANCO DO BRASIL, 2010). Sua produção apresentou crescimento constante durante o período de 2005 a 2015, período em que saltou de aproximadamente 24,62 bilhões de litros em 2005 para 35 bilhões de litros em 2015, obtendo assim um aumento de $43 \%$, segundo dados do Instituto Brasileiro de Geografia e Estatística - IBGE (IBGE, 2015a), números estes que dão ao Brasil a sexta posição no ranking mundial de produção de leite, ficando atrás de União Europeia, EUA, Índia, China e Rússia (USDA, 2015a).

Segundo Stock et al. (2008), o crescimento pode ser atribuído a dois fatores. O primeiro é o aumento do número de vacas ordenhadas, o qual obteve um crescimento de 112,80\% nos últimos 40 anos, saltando de 10,83 milhões de animais em fase de lactação em 1974 para 23,06 milhões em 2014 (IBGE, 2015b). O segundo fator é a adoção de animais de maior produtividade no sistema de produção leiteiro, no qual se destaca o aumento de $54 \%$ na sua produtividade no período compreendido entre 2003 e 2013, sendo, atualmente, a média de 1.525 litros/vacas/ano (IBGE, 2015c).

Na bovinocultura de leite, apesar de desenvolver-se em todo território nacional, não existe um padrão de produção, fazendo com que haja uma grande discrepância entre as Unidades da Federação produtoras, chegando a ter propriedades com média diária menor que 10 litros e outras com índices superiores a 65 mil litros diários (ZOCCAL et al., 2008; DUARTE; CAVALCANTI, 2016). É também considerada uma atividade de baixa rentabilidade ao produtor, o que faz com que mais de 90\% dos produtores sejam considerados pequenos, ou seja, com baixo volume de produção e com uso de baixo ou nenhum nível tecnológico. Note-se que apenas 2,3\% das propriedades são especializadas na atividade leiteira, funcionando como empresa rural (GONÇALVES et al., 2014; PARANÁ, 2016).

Destaca-se, como maior produtor nacional de leite, o Estado de Minas Gerais, com 9,37 bilhões de litros produzidos, o que corresponde ao equivalente de $76,83 \%$ de toda produção da Região Sudeste e de 26,12\%, se comparado à produção total brasileira (IBGE, 2015a).

Por outro lado, a posição do Brasil, no que se refere ao número de vacas ordenhadas, é apenas a terceira no ranking mundial, com 21,3 milhões de vacas ordenhadas, obtendo uma representatividade de 14,9\% de participação no total de vacas em lactação. Tem-se, por destaque, a Índia, a qual possui um rebanho com total de 52,5 milhões de vacas, com representatividade de 36,6\% destas em lactação (MAIA et al., 2013; USDA, 2015b).
Segundo Ramos et al. (2014), a pecuária leiteira do Brasil vem passando por um processo de modernização, mudança esta que, segundo os referidos autores, só ocorrerá com a especialização dos produtores. De acordo com Silva et al. (2013), o processo para a implantação de tecnologia de automação para a produção e qualidade leiteira tem ocorrido de maneira lenta e sucessiva, sendo atribuído, ao fator financeiro, o maior limitador de sua implantação (CAMPOS et al., 2016; VILELA et al., 2017). A produtividade nos sistemas de produção de leite em áreas de clima tropical é baixa em todo o mundo, se comparada aos sistemas implantados em locais de clima temperado. Este comportamento é explicado pela soma de vários fatores que interagem, mas sendo, principalmente, a interação entre o potencial genético dos animais que compõem os rebanhos e as condições edafoclimáticas hostis, consideradas os principais causadores desta baixa produtividade em regiões com características como a do nosso país, de clima tropical, associado com um dos contratempos na atividade leiteira (SIMÕES, 2014).

Nos esforços para obter uma melhoria na produtividade em sistemas com essas características, buscou-se utilizar uma ferramenta de melhoria genética dos rebanhos, que foi o cruzamento de raças zebuínas, que apresentam excelente adaptação às condições tropicais, com raças de origem europeia especializadas para produção de leite (TORQUATO et al., 2017; RAIDAN et al., 2015).

Este fator foi importante e merece destaque por sua contribuição para o aumento na produtividade da pecuária leiteira dos últimos anos, juntamente com a adoção e utilização de tecnologias de automatização do processo produtivo, que contribuíram com a melhoria dos fatores de produção (VILELA, 2011; DANTAS, 2014). Desta forma, pode-se afirmar que o melhoramento na genética de nossos rebanhos leiteiros teve importante participação no aumento de produção nos últimos anos, com o aumento da participação das raças europeias na composição dos rebanhos, que hoje são compostos predominantemente por animais mestiços (Holandês $\times$ Zebu). Assim, como houve também melhoramento dos animais Zebu, que já faziam parte de rebanhos brasileiros para leite, sendo, principalmente, animais das raças Gir e Guzerá. Podemos citar também o expressivo aumento na participação da raça Jersey, especialmente em cruzamento com a raça Holandês, sendo este cruzamento entre animais das duas raças considerado um dos mais disseminados pelo mundo (THALER NETO et al., 2013; KNOB, 2015; COSTA et al., 2016).

Nesse sentido, Dias e Almeida (2013) realizaram estudos da relação existente entre as produções tecnológica - por meio de patentes - versus científica, atribuída à análise econômica relacionada ao processo de inovação. Dessa forma, estudos de prospecção tecnológica têm sido realizados a fim de avaliar o processo evolutivo da tecnologia inserida na indústria e as suas influências 
diretas na economia e na sociedade (CASTRO; VON KRUGER, 2013).

A partir da hipótese de o aumento da produção de leite estar vinculado apenas ao aumento dos números de animais ordenhados, objetivou-se, no presente trabalho, levantar e analisar o número de patentes registradas junto ao INPI sobre a produção e qualidade leiteira de bovinos e correlaciona-lo com a produção nas últimas décadas.

\section{Material e métodos}

Foram consultadas, durante o ano de 2016, as bases de dados do Instituto Nacional da Propriedade Industrial (INPI, 2016), disponibilizadas na internet, sobre os pedidos das patentes relacionadas à produção leiteira.

A busca ocorreu de acordo com a Classificação Internacional de Patentes (CIP), seguindo suas ramificações feitas durante o processo de registros das patentes nas bases de dados do INPI. De início, foi consultada a Seção A, que se refere a Necessidades Humanas; dentre quatro subseções inseridas, buscou-se subseção (A0), relacionada à Agricultura, que abrange 13 subclasses de registros, nas quais se insere o objetivo desta pesquisa, mais especificamente na referência A01J - Manufaturas de Produtos Lácteos. Foi de interesse deste trabalho apenas os registros relacionados à ordenha; assim, obtêm-se quatro classes de interesse para a pesquisa, abrangente a processos relacionados à produção leiteira: A01J 1/00 (Dispositivo ou acessório para ordenha manual); A01J 3/00 (Ordenha com cateteres); A01J 5/00 (Dispositivos para ordenha mecânica) e A01J 7/00 (Acessórios para máquinas de ordenha ou dispositivo) (INPI, 2016).

A metodologia empregada focou-se no número total de registros de patentes que obedeceram ao escopo da pesquisa, que teve como objetivo quantificar as patentes relacionadas à produção leiteira.

Os dados referentes a produção leiteira, número de animais e produtividade foram obtidos junto ao site do IBGE e, dessa maneira, correlacionados com os dados coletados do site do INPI.

Para analisar os dados sobre a produção e o número de patentes, empregou-se a análise descritiva, pela qual se buscou investigar o número de patentes produzidas por ano, assim como, a produção leiteira e as vacas em ordenha. A fim de verificar a correlação entre as variáveis supracitadas, empregou-se a Correlação de Pearson com a $\alpha=5 \%$, utilizando-se o software SigmaPlot para a confecção dos gráficos e para as análises estatísticas.

\section{Resultados e discussão}

Foi encontrado um total de 132 registros de patentes na base de dados do INPI, no período de 1975 a 2015, as quais estão representadas na Figura 1.

Observa-se, no período analisado, que ocorreu o aumento de registros de patentes após 1996, período em que foi promulgada a Lei n. 9.279 (BRASIL, 1996), que regula os direitos e obrigações relativos à propriedade industrial, dando ampla proteção e incentivo a pesquisadores e empresários do ramo tecnológico que buscam, na exclusividade, uma solução técnica para um determinado problema.

No entanto, no ano de 2002, foi publicada pelo Ministério da Agricultura, Pecuária e Abastecimento (MAPA), a Instrução Normativa n. ${ }^{\circ} 51$ (IN 51), com o objetivo de regulamentar a produção, a qualidade, a coleta e o transporte dos leites tipo A, tipo B, tipo $C$, pasteurizado e cru refrigerado, a qual entrou em vigor apenas em julho de 2005, o que possivelmente explica o aumento expressivo do número de registros das patentes a partir daquele ano (CALLEFE; LANGONI, 2015; BRASIL, 2002a,b).

Entre 1975 e 1996, foi contabilizado um total de 23 patentes registradas vinculadas ao processo de ordenha, o que representa apenas $17,2 \%$ da base de dados do INPI referente ao processo analisado, possuindo uma demanda de 1,21 patente por ano. No período após a instalação da Lei n. 9.279 até 2005, ano em que entrou em vigor a IN 51, há um total de 36 patentes, com uma procura de 1,88 patente/ano. Por outro lado, após 2005 até 2015, existe um total de 74 registros de patentes, que nos mostra um total de 10,3 registros/ano, além de concentrar um total de $55,64 \%$ de toda a base de registro do INPI relacionada ao processo de ordenha.

As patentes encontradas foram quantificadas segundo sua classificação de registro pelo INPI, conforme podemos observar na Tabela 1.

Os processos que obtiveram maior quantidade de registros foram os relacionados a dispositivos para ordenha mecânica (A01J 5/00), totalizando 22 patentes, seguida pela especificidade para manipulação pneumática das

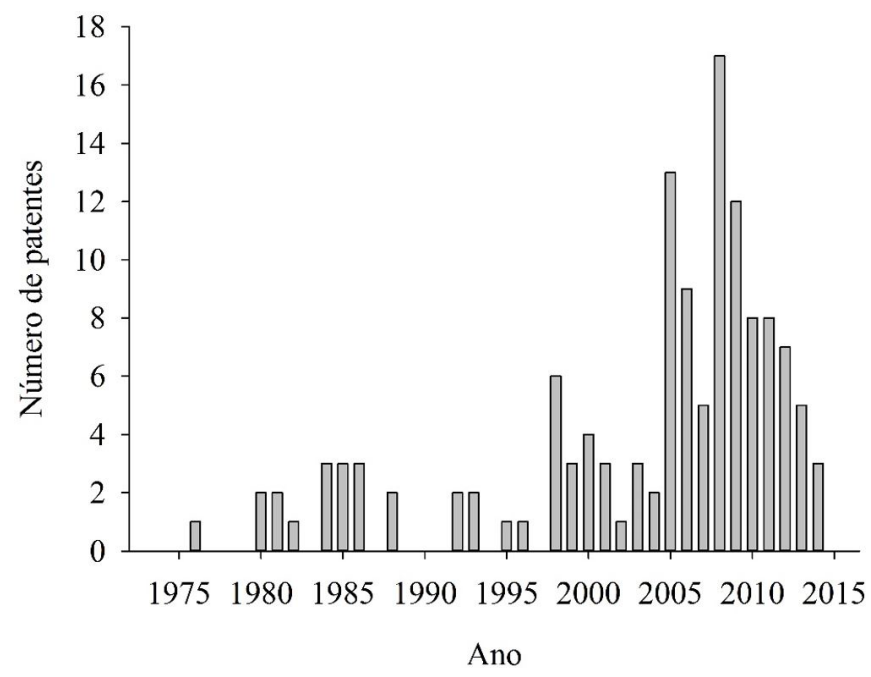

Figura 1. Número de patentes relacionado a produção de leite entre os anos de 1975 a 2015. 
Análise da evolução do número de patentes relacionadas ao processo de ordenha

Putti, F. F. et al.

Tabela 1. Classificação das patentes de acordo o INPI (2016) e o número de registros no período de 1975 a 2015.

\begin{tabular}{|c|c|c|}
\hline Código & Descrição & Quantidade \\
\hline A01J $1 / 00$ & Dispositivos ou acessórios para ordenha manual & 3 \\
\hline A01J 5/00 & Dispositivos para ordenha mecânica & 22 \\
\hline A01J 5/003 & Dispositivos para ordenha mecânica / Máquinas para ordenha móveis & 4 \\
\hline A01J 5/007 & $\begin{array}{l}\text { Dispositivos para ordenha mecânica / Monitoramento dos processos de ordenha; Controle ou } \\
\text { regulação das máquinas de ordenha }\end{array}$ & 9 \\
\hline A01J 5/01 & $\begin{array}{l}\text { Dispositivos para ordenha mecânica / Monitoramento dos processos de ordenha/ Controle ou } \\
\text { regulação das máquinas de ordenha / Medidores de leite; dispositivos sensores do fluxo do leite }\end{array}$ & 5 \\
\hline A01J 5/013 & Dispositivos para ordenha mecânica / Detecção no local de mastite no leite & 1 \\
\hline A01J 5/017 & Dispositivos para ordenha mecânica / Conexão ou desconexão automática dos jatos & 3 \\
\hline A01J 5/02 & Dispositivos para ordenha mecânica / com manipulação mecânica das tetas & 1 \\
\hline A01J 5/04 & Dispositivos para ordenha mecânica / com manipulação pneumática das tetas & 16 \\
\hline A01J 5/06 & $\begin{array}{l}\text { Dispositivos para ordenha mecânica / com manipulação pneumática das tetas; / Cubas para tetas } \\
\text { com um compartimento }\end{array}$ & 3 \\
\hline A01J 5/08 & $\begin{array}{l}\text { Dispositivos para ordenha mecânica / com manipulação pneumática das tetas; / Cubas para tetas } \\
\text { com dois compartimentos }\end{array}$ & 15 \\
\hline A01J 5/10 & Dispositivo para ordenha mecânica / Pulsadores dispostos de outro modo que não nas cubas para tetas & 4 \\
\hline A01J 5/12 & $\begin{array}{l}\text { Dispositivo para ordenha mecânica / com manipulação pneumática das tetas / Pulsadores } \\
\text { dispostos de outro modo que não nas cubas para tetas / com membranas }\end{array}$ & 5 \\
\hline A01J 5/16 & $\begin{array}{l}\text { Dispositivo para ordenha mecânica / com manipulação pneumática das tetas; / Cubas para tetas } \\
\text { com dispositivos pulsantes }\end{array}$ & 3 \\
\hline A01J $7 / 00$ & Acessórios para máquinas de ordenha ou dispositivos & 15 \\
\hline A01J 7/02 & $\begin{array}{l}\text { Acessórios para máquinas de ordenha ou dispositivos / para limpeza ou saneamento das } \\
\text { máquinas de ordenha ou dispositivos }\end{array}$ & 13 \\
\hline A01J $7 / 04$ & Acessórios para máquinas de ordenha ou dispositivos / para tratamento de úberes ou tetas, p. ex. para limpeza & 10 \\
\hline
\end{tabular}

tetas (A01J 5/04), com 16 registros, sendo que 15 patentes registradas na base de dados são as de especificidade de cubas para tetas com dois compartimentos (A01J 5/08), apresentando igual quantidade para acessórios para máquinas de ordenha ou dispositivo, com codificação A01J 7/00. Dentro dessa especificidade, encontram-se 13 registros para limpeza ou saneamento das máquinas de ordenhas ou dispositivos (A01J 7/02), seguidos das patentes específicas para tratamento de úberes ou tetas, com 10 registros (A01J 7/04).

Por outro lado, o número total de animais em fase de ordenha no Brasil manteve-se crescente por quase todo o período analisado, exceto nos anos de 1995 e 1996, sofrendo uma queda brusca de vacas em lactação (Figura 2).

Uma das possíveis causas da queda do número de animais ordenhados em 1995 pode ser atribuída ao surto de febre aftosa no Brasil, ocorrido entre os anos de 1992 e 1994, época em que o gado era utilizado como moeda de troca em leilões pelo país, estimulado pelo plano econômico de 1990, o que facilitou a disseminação da doença pelo território brasileiro, aglomerando animais de diferentes procedências. A Tabela 1 , referente à febre aftosa, mostrou melhora após o plano econômico Real instituído em 1994, em que houve uma redução dos leilões, além do plano nacional de vacinação do rebanho contra a doença (LYRA; SILVA, 2004).

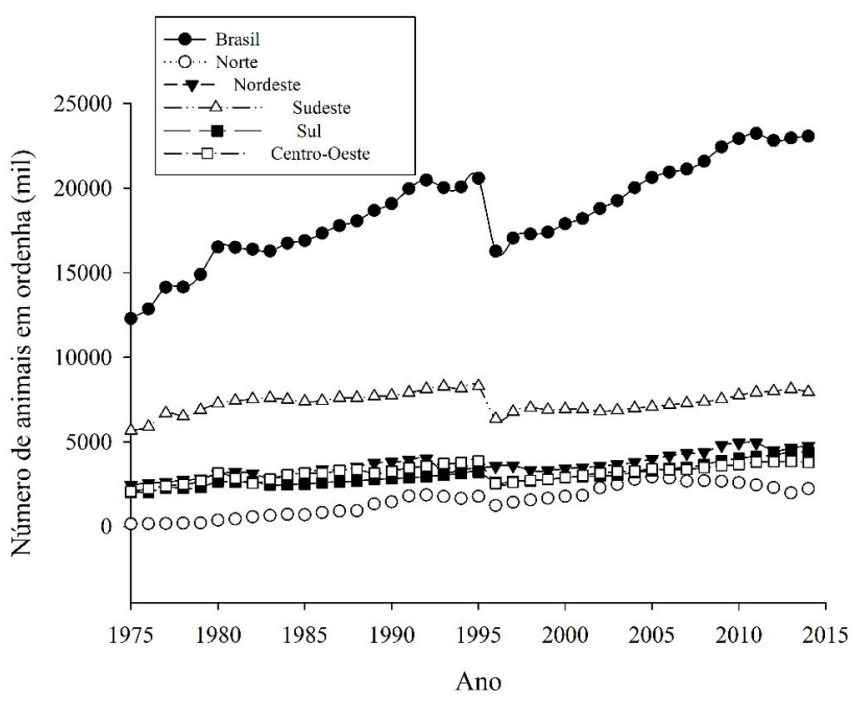

Figura 2. Número de animais em ordenha entre os anos de 1974 a 2015.

O gráfico a seguir (Figura 3) mostra a produção leiteira entre 1990 e 2015.

Como mencionado anteriormente, o Brasil os animais mestiços zebuínos são os de maior representatividade na produção de leite, com destaque dado para os mestiços resultantes do cruzamento das raças Holandês $\times$ Gir (RAIDAN et al., 2015). Com base nos fatos apresentados, 
Análise da evolução do número de patentes relacionadas ao processo de ordenha

Putti, F. F. et al.

podemos afirmar que o melhoramento genético do rebanho leiteiro brasileiro representou um fator de grande importância no aumento da produção e qualidade do leite, comportamento este observado ao longo das últimas décadas. Corroborando com este fato, Ledic e Tetzner (2008) afirmaram que a produção de leite na faixa tropical do Brasil tem como base a utilização de vacas mestiças de taurinos com zebuínos, que representam uma proporção estimada na ordem de 59,78\% da produção nacional (GRÁZIA et al., 2016).

Outros autores ressaltam que os sistemas de produção predominantes são baseados em pastagens com suplementação e com vacas mestiças. Desta forma, o Brasil possui um dos maiores rebanhos mestiços do mundo e a produção de gado de leite na parte tropical do Brasil está baseada majoritariamente em animais mestiços de Bos taurus taurus $\times$ Bos taurus indicus, sendo - Holandês a principal raça taurina (MARIANTE et al., 2003; MCMANUS et al., 2008; PRATA et al., 2013).

Na Tabela 2, podemos ver os índices de correlação existentes entre os fatores: números de patentes e animais em ordenha; número de patentes e produção, e animais em ordenha e produção.

Verificou-se a existência de correlação entre os fatores estudados: número de patentes e número de animais em ordenha; número de patentes e produção de leite; assim como o número de animais em ordenha com

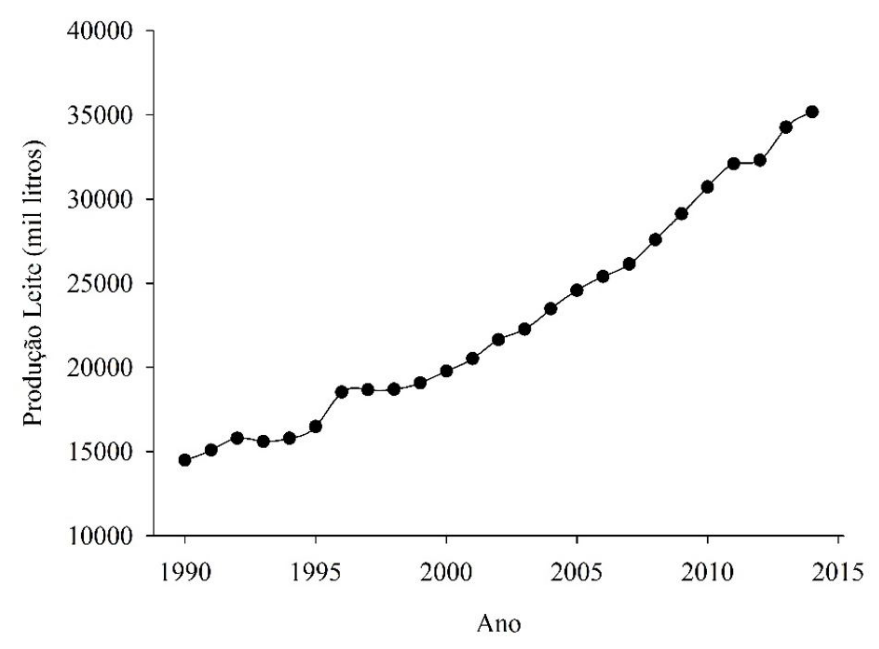

Figura 3. Produção de leite no Brasil entre os anos de 1990 a 2014.

Tabela 2. Correlação entre o número de patentes geradas, números de animais em ordenha e produção de leite.

\begin{tabular}{lcc} 
& $\begin{array}{c}\text { Número de } \\
\text { patentes }\end{array}$ & $\begin{array}{c}\text { Número de } \\
\text { animais ordenha }\end{array}$ \\
$\begin{array}{l}\text { Números de animais } \\
\text { em ordenha }\end{array}$ & 0.28 & - \\
Produção de leite & $0.73^{*}$ & $0.72^{*}$ \\
\hline
\end{tabular}

*significativo para $p<0.05$. a produção leiteira. Foi constatado um índice de 0,28 (28\%) entre número de patentes e número de animais em ordenha, significando a não que indica que não há correlação entre essas duas variáveis estudadas. Por outro lado, quando analisadas as variáveis de número de patentes e produção leiteira, verificou-se significância de $0,73(73 \%)$ com $p<0,05$. Do mesmo modo, verificou-se correlação significativa entre o número de animais em fase de ordenha e o aumento da produção leiteira, com índice de 0,72 (72\%) com $p<0,05$.

\section{Conclusões}

Pode-se concluir que o aumento do número de patentes no período de 1975 a 2015 coincide com o incremento da produção leiteira. Esse incremento é consequência do maior número de animais ordenhados e da maior produtividade leiteira no rebanho. Assim, a evolução tecnológica do setor, que se refletiu no aumento do número de patentes, fazendo-se menção ao melhoramento da qualidade dos produtos lácteos.

\section{Referências}

ARAÚJO, L. V.; SILVA, S. P. Agricultura familiar, dinâmica produtiva e estruturas de mercado na cadeia produtiva do leite: elementos para o desenvolvimento territorial no Noroeste de Minas. Revista Brasileira de Gestão e Desenvolvimento Regional, v. 10, n. 1, p. 52-79, 2014

BANCO DO BRASIL. Desenvolvimento regional sustentável. Brasília: Banco do Brasil, 2010. (Série cadernos de propostas para atuação em cadeias produtivas. Bovinocultura de leite, vol. 1),

BRASIL. Lei n 9.394, de 20 de dezembro de 1996. Estabelece as diretrizes e bases da educação nacional. Diário Oficial [da] República Federativa do Brasil, Brasília, DF, v. 134, n. 248. Seção I, p. 27834-27841, 1996

BRASIL. Instrução Normativa n 51 de 18 de setembro de 2002. Aprova os Regulamentos Técnicos de Produção, Identidade e Qualidade do Leite tipo A, do Leite tipo B, do Leite tipo C, do Leite Pasteurizado e do Leite Cru Refrigerado e o Regulamento Técnico da Coleta de Leite Cru Refrigerado e seu Transporte a Granel. Diário Oficial [da] República Federativa do Brasil, Brasília, DF, Seção 1, p. 13, $2002 a$.

BRASIL. Ministério da Agricultura, Pecuária e Abastecimento. Informações gerais sobre a Instrução normativa $n^{\circ}$. 51. Brasília: MAPA, 2002b. Disponível em: <http://www.agricultura.gov.br/>. Acesso em: 27 ago. 2016

CALLEFE, J. L.; LANGONI, H. Qualidade do leite: uma meta a ser atingida. Veterinária e Zootecnia, v. 22, n. 2, p. 151-162, 2015.

CAMPOS, L. C.; BORGES, W. G.; TAVARES, M.; SANTOS, G. C.; CARVALHO, L. F. Análise de cluster: segmentação de mercado na produção leiteira do estado de São Paulo. Revista de Auditoria Governança e Contabilidade, v. 4, n. 16, p. 47-62, 2016. 
Análise da evolução do número de patentes relacionadas ao processo de ordenha

Putti, F. F. et al.

CASTRO, M.; VON KRUGER, P. G. Unidades de seleção tecnológica e inovação na construção habitacional no Brasil. Ambiente Construído, v. 13, n. 3, p. 217-233, 2013. http:// dx.doi.org/10.1590/S1678-86212013000300013

COSTA, M. D.; RUAS, J. R. M.; RODRIGUEZ, M. A. P.; NOGUEIRA, T. M.; VENTURINI, R. P. Análise da relação benefício-custo em sistema de produção de leite com animais mestiços no Norte de Minas Gerais. Boletim de Indústria Animal, v. 73, n. 3, p. 244-251, 2016. http://dx.doi.org/10.17523/bia.v73n3p244.

DANTAS, V. V. Caracterização dos sistemas de produção na bovinocultura leiteira nas mesorregiões sudeste e nordeste paraense. 2014. 87 f. Dissertação (Mestrado em Ciência Animal)Programa de Pós-graduação em Ciência Animal, Universidade Federal do Pará, Belém, 2014.

DIAS, C. G.; ALMEIDA, R. B. Produção científica e produção tecnológica: transformando um trabalho científico em pedidos de patente. Einstein (São Paulo), v. 11, n. 1, p. 1-10, 2013

DUARTE, V. N.; CAVALCANTI, K. A. Evolução e concentração inter-regional e intra-regional da produção de leite: o caso do estado de Santa Catarina no período de 2000 a 2012. Evidência - Ciência e Biotecnologia, v. 15, n. 2, p. 153-164, 2016.

GONÇALVES, A. C. S.; ROMA JÚNIOR, L. C.; FONSECA, M. I.; NADRUZ, B. V.; BURGER, K. P.; ROSSI, G. A. M. Assistência técnica e extensão rural: um estudo de caso que demonstra sua importância para a melhoria da produção leiteira. Revista Brasileira de Higiene e Sanidade Animal, v. 8, n. 3, 2014.

GRÁZIA, J. G. V.; SILVEIRA, R. O.; PEREIRA, E. C. M.; SANTOS, G. M. Desempenho de doadoras leiteiras mestiças F1 (Gir $x$ Holandês) no sistema de produção in vitro de embriões. Arquivo Brasileiro de Medicina Veterinária e Zootecnia, v. 68, n. 3, p. 605-610, 2016. http://dx.doi.org/10.1590/1678-4162-8317.

INSTITUTO BRASILEIRO DE GEOGRAFIA E ESTATÍSTICA IBGE. Produção de origem animal, por tipo de produto. Rio de Janeiro: IBGE, 2015a. Disponível em: <http://www.sidra.ibge. gov.br/bda/tabela/protabl.asp?c $=74 \& z=t \& 0=24 \& \mathrm{i}=\mathrm{P}>$. Acesso em 12 set. 2016

INSTITUTO BRASILEIRO DE GEOGRAFIA E ESTATÍSTICA - IBGE. Efetivo dos rebanhos, por tipo de rebanho. Rio de Janeiro: IBGE, 2015b. Disponível em: <http://www.sidra.ibge.gov.br/ bda/tabela/protabl.asp?c $=3939 \& z=t \& o=24 \& i=P>$. Acesso em: 12 set. 2016.

INSTITUTO BRASILEIRO DE GEOGRAFIA E ESTATÍSTICA IBGE. Pesquisa Pecuária Municipal. Rio de Janeiro: IBGE, 2015c. Disponível em: <http://www.ibge.gov.br/home/estatistica/ economia/ppm/2015/default_sidra.shtm>. Acesso: 6 out. 2016.

INSTITUTO NACIONAL DE PROPRIEDADE INDUSTRIAL - INPI. Base de dados: pesquisa em propriedade industrial. Rio de Janeiro: IBGE, 2016. Disponível em: <https://gru.inpi.gov.br/pePI/ jsp/patentes/PatenteSearchBasico.jsp>. Acesso em: 6 out. 2016.
KNOB, D. A. Crescimento, desempenho produtivo e reprodutivo de vacas Holandês comparadas às mestiças Holandês $x$ Simental. 2015. 100 f. Dissertação (Mestrado em Ciência Animal)-Universidade do Estado de Santa Catarina, Lages, 2015.

LEDIC, I. L.; TETZNER, T. A. D. Grandezas do Gir Leiteiro: o milagre zootécnico do século XX. Uberaba: 3 Pinti, 2008.

LYRA, T. M. P.; SILVA, J. A. A febre aftosa no Brasil, 1960-2002. Arquivo Brasileiro de Medicina Veterinária e Zootecnia, V. 56, n. 5, p. 565-576, 2004. Disponível em: <http://www.scielo. br/pdf/abmvz/v56n5/a01v56n5.pdf>. Acesso em: 5 jan. 2017.

MAIA, G. B. S.; PINTO, A. R.; MARQUES, C. Y. T.; ROITMAN, F. B.; LYRA, D. D. Produção leiteira no Brasil. Banco Nacional de Desenvolvimento Econômico e Social -BNDES Setorial, v. 37, p. 371-398, 2013.

MARIANTE, A. S.; MCMANUS, C.; MENDONÇA, J. F. Country report on state of animal genetic resources Brasil. Brasília: Embrapa Recursos Genéticos e Biotecnologia, 2003. 121 p. (Documentos 99).

MCMANUS, C.; TEIXEIRA, R. D. A.; DIAS, L. T.; LOUVANDINI, H.; OLIVEIRA, E. M. B. Características produtivas e reprodutivas de vacas Holandesas e mestiças Holandês $\times$ Gir no Planalto Central. Revista Brasileira de Zootecnia, v. 37, n. 5, p. 819-823, 2008. http://dx.doi.org/10.1590/S1516-35982008000500006.

PARANÁ. Governo do Estado. Secretaria da Agricultura e Abastecimento - SEAB, Departamento de Economia Rural DERAL, Divisão de Conjuntura Agropecuária - DCA. Análise da conjuntura agropecuária: leite. Curitiba: SEAB, 2016.

PRATA, M. A.; MOREIRA, H. L.; VERCESI FILHO, A. E.; VERNEQUE, R. S.; CARDOSO, V. L.; EL FARO, L. Parâmetros genéticos para características de produção e qualidade do leite para a raça Gir leiteiro. In: SIMPÓSIO BRASILEIRO DE MELHORAMENTO ANIMAL, 10., 2013, Uberaba. Anais... Sertãozinho: SBMA, 2013. p. 1-3. Disponível em: <http://sbmaonline.org.br/anais/x/ trabalhos/pdf/6MXM.pdf>. Acesso em: 5 jan. 2017.

RAIDAN, F. S. S.; COSTA, M. D.; RUAS, J. R. M.; ROCHA JUNIOR, V. R.; SILVA, E. A.; SANTIAGO, R. L.; RIBEIRO, A. M. F.; RIBAS, W. F. G. Desempenho produtivo e reprodutivo de fêmeas F1 Holandês x Nelogir. Revista Brasileira de Saúde e Produção Animal, v. 16, n. 3, p. 678-687, 2015. http://dx.doi.org/10.1590/ S1519-99402015000300018.

RAMOS, M. C.; CAMPOS, A. T.; TADAYUKI JÚNIOR, Y.; SILVA, K. C. $P$. Sustentabilidade na produção de leite: balanço energético em sistema intensivo de produção com visão focada nos processos. Engenharia Agrícola, v. 34, n. 3, p. 473-484, 2014. http://dx.doi. org/10.1590/S0100-69162014000300011.

SILVA, I. M.; PANDORFI, H.; VASCONCELOS, A. J. S.; LAURENTI, R.; GUISELINI, C. Automação no controle do microclima na pré-ordenha de bovinos leiteiros. Revista de Engenharia Agrícola, v. 33, n. 1, p. 1-10, 2013. 
Análise da evolução do número de patentes relacionadas ao processo de ordenha

Putti, F. F. et al.

SIMÕES, G. H. Avaliação de estresse térmico em vacas de leite em Free Stall sob diferentes condições de climatização. 2014. 75 f. Dissertação (Mestrado em Ciência Animal)-Programa de Pós-graduação em Ciências Animal, Universidade Federal do Paraná, Palotina, 2014.

SOUZA, J. B. L.; ALVES, A. F.; CULTI, M. N. A pecuária leiteira e o risco de exclusão nos municípios de Peabiru e Quinta do Sol. Interações, v. 14, n. 2, p. 203-211, 2013.

STOCK, L. A.; CARVALHO, G. R.; ZOCCAL, R.; MARTINS, P. C.; YAMAGUCHI, L. C. T. Sistema de produção e sua representatividade na produção de leite no Brasil. In: REUNIÃO DA ASSOCIAÇÃO LATINO-AMERICANA DE PRODUÇÃO ANIMAL, 2008, Cuzco. Anais... Cuzco, Peru: ALPA, 2008. p. 17-18.

THALER NETO, A.; RODRIGUeS, R. S.; CÓRDOVA, H. A. Desempenho produtivo de vacas mestiças Holandês $x$ Jersey em comparação ao Holandês. Revista de Ciências Agroveterinárias, v. 12, n. 1, p. 7-12, 2013.

TORQUATO, I. A.; EL FARO, L.; MASCIOLLI, A. S. Desempenho produtivo e curva de lactação de animais mestiços holandês x gir na região agreste de Pernambuco. Boletim de Indústria
Animal, v. 74, n. 1, p. 27-35, 2017. http://dx.doi.org/10.17523/ bia.v74n1p27.

UNITED STATES DEPARTMENT OF AGRICULTURE - USDA. Dairy: world markets and trade. USA: USDA, 2015a. Disponível em: <https://apps.fas.usda.gov/psdonline/circulars/dairy.pdf>. Acesso em: 12 set. 2016.

UNITED STATES DEPARTMENT OF AGRICULTURE - USDA. Statistics of cattle, hogs, and sheep. USA: USDA, 2015b. Disponível em: <https://www.nass.usda.gov/Publications/ Ag_Statistics/2015/Chapter07.pdf>. Acesso em: 12 set. 2016.

VILELA, D. Sistema de produção de leite para diferentes regiões do Brasil. Juiz de Fora: EMBRAPA - Gado de leite, 2011.

VILELA, D.; RESENDE, J. C.; LEITE, J. B.; ALVES, E. A evolução do leite no Brasil em cinco décadas. Revista de Política Agrícola, v. 26, n. 1, p. 5-24, 2017.

ZOCCAL, R.; CARNEIRO, A. V.; JUNQUEIRA, R.; ZAMAGNO, M. A nova pecuária leiteira brasileira. In: CONGRESSO BRASILEIRO DE QUALIDADE DE LEITE, 2008, Recife. Anais... Curitiba: RBQL, 2008. p. 85-95. 